\title{
Behavioral finance from a practitioner's viewpoint
}

In my work advising individuals on their investment strategies, I get somewhat of a front-row seat when it comes to observing behavioral investing in action. More than occasionally, I find myself explaining to a client why his or her desired course of action is likely to do more harm than good. But knowledge of market conditions and historical risk/return dynamics is hardly the sole determinant of such advice. Rather, good decision-making begins with knowing what causes people to act in the first place.

Indeed, one of the most important functions of an investment advisor is to help clients manage the basic human impulses of fear, regret and greed - a service that, as it turns out, individual investors value. And it's not just individuals; even some of the most sophisticated institutions, regulators and corporate managers have a predilection to the herd mentality, especially during periods of extreme volatility. For those of us focused on the risk side of the equation, understanding the behavioral component of the decision-making process is essential to our understanding of market dynamics - particularly in periods of financial stress like the past decade, in which we saw two equity market corrections of approximately $50 \%$ each.

As investment practitioners, we can use these behavioral insights to do more than simply help our clients avoid making costly mistakes when they are seized by the "fight or flight" instinct; we can factor human behavior into our investment and risk management strategies themselves. While markets are reasonably efficient, they do not and cannot account for the fact that investors are human beings who do not always act rationally. The good news in all of this is that many of these cognitive biases are so prevalent and well documented that savvy and objective investors can actually profit from them.
For example, we know that fear all too often drives investors out of the market when sentiment is low, and yet research has shown that those investors who actually buy equities during these periods end up outperforming their peers who joined the crowd of sellers. Behavioral explanations also exist for the phenomenon of momentum - the tendency of winning stocks to keep winning and losers to keep losing - allowing investors with the ability to engineer tilts in their portfolio to this theme to harness a new source of expected return. Often it is enough to simply consciously and objectively acknowledge that some of the current market trends are driven by sentiment, not good investing sense, and to make one's own investment decisions accordingly.

Certainly the recent global financial crisis has provided rich illustrations of some of the effects of investor behavior on markets. For example, we learned the high price that people will pay for any measure of liquidity when gripped by fear. We witnessed many investors, jolted by high market volatility and the precipitous plunge in global equity markets, exit the markets in droves in 2008 - only to miss out on the extraordinary upswing that started the following year.

Every day, investment advisors are faced with the challenge of recommending rational investment strategies to behavioral investors. As long as investors are human, this challenge will remain. There is much we can do, however, to address it, both in the thoughtful advice and guidance we provide that help investors "get out of their own way", and within the very investment strategies we employ on their behalf.

Gregg S. Fisher CFA, $C F P^{\circledR}$ Gerstein Fisher New York, NY, USA 